
\title{
28 Research Square \\ Morbidity among Arab-Israeli and Palestinian Hajj Pilgrims - a Prospective study
}

\section{Bashar Fteiha}

Shaare-Zedek Medical Center, https://orcid.org/0000-0001-7676-9447

\section{Tawfiq Abul Rub}

Chaim Sheba Medical center, Tel-Hashomer, Israel

\section{Eli Schwartz}

The Center for Travel and Tropical Medicine, Sheba Medical Center, Tel Hashomer and the Sackler School of Medicine, Tel Aviv University, Israel

Tamar Lachish ( $\square$ lachisht@szmc.org.il)

Shaare-Zedek Medical Center

\section{Research Article}

Keywords: mass gathering, pilgrimage, Hajj

Posted Date: November 5th, 2020

DOI: https://doi.org/10.21203/rs.3.rs-92800/v1

License: (c) (1) This work is licensed under a Creative Commons Attribution 4.0 International License. Read Full License

Version of Record: A version of this preprint was published at The American Journal of Tropical Medicine and Hygiene on April 7th, 2021. See the published version at https://doi.org/10.4269/ajtmh.20-1460. 


\section{Abstract}

Background - Thousands of Palestinian and Arab-Israeli pilgrims travel to Mecca each year to complete their pilgrimage. We prospectively investigated the occurrence of healthproblems among these Hajjis who travelled to complete their Pilgrimage during 2019 Hajj season.

Methods - A prospective observational questionnaire-based study, distributed to Hajj pilgrims at 3 occasions - before travel, inquiring on demographics, and medical comorbidities; 1 and 4 weeks after returning recording any health problem during or after travel.

Results - Initial recruitment included 111 Hajjis. The mean age of responders was $49.5(+9.137)$ years with a M:F ratio of 1.3:1. Mean travel-duration was 18.7 days (13-36d). Altogether, $66.3 \%$ of the pilgrims reported at least one health problem during and after the trip, of which $38.6 \%$ sought medical attention. Five (4.8\%) hajjis were hospitalized including life-threatening conditions. Cough was the most common complaint (53.8\%), 11.5\% also reported fever. Pre-travel counselling was associated with reduced outpatient and Emergency Room visits.

Conclusion - A high rate of morbidity was reported among this cohort of Hajj pilgrims with a morbidity spectrum similar to pilgrims from other countries. Pre-travel consultation with the purpose of educating on the health risks of Hajj may help reduce the morbidity for future Hajj seasons.

\section{Introduction}

The World Health Organization (WHO) defines mass gatherings as "events attended by a sufficient number of people to strain the planning and response resources of a community, state or nation" [1][2] One of the major public health concerns in relation to mass gatherings is the importation or exportation of infectious diseases, and spread between attendees, to the local population, and back to their countryof-origin. Examples of such mass gathering events include the Olympic games and the Kumbha Mela religious festival in India.

As the largest annual mass gathering in the world, the hajj or pilgrimage to Mecca is of central importance to the Muslim nation being the fifth pillar of Islam and a duty for all able-bodied financially capable Muslims [3].

Almost ten thousand Palestinian and Arab-Israeli pilgrims make their way to Mecca each year to complete their pilgrimage [4]. The absence of any direct diplomatic relations between Saudi Arabia and Israel makes the participation of Arab-Israeli pilgrims a rather complex and unique situation. The entry of these pilgrims to Saudi Arabia is not possible with an Israeli passport, and the lack of any direct flights between both countries leaves Jordan as the only viable route to Mecca with pilgrims entering Saudi Arabia with temporary Jordanian passports obtained in Jordan. Whereas the Palestinian Hajj affairs are handled directly by the Palestinian ministry of Awqaf and Religious Affairs, the Kingdom handles all the administrative and logistical apparatus for organizing the pilgrimage operating through a local hajj And 
Umrah Committee based in Israel. This single-source arrangement means Arab-Israeli pilgrims often have to pay exorbitant prices for their pilgrimage.

Preparation for the Hajj journey starts several months before the travel. For the purpose of obtaining a Hajj visa, all hajjis including Palestinian and Arab Israelis are required to submit a proof of valid quadrivalent (ACYW) meningococcal vaccine within the last 3-5 years, administered not less than 10 days prior to the planned arrival in Saudi Arabia [5]. Influenza vaccine is also recommended but not obligatory for travelling pilgrims [6]. Palestinian pilgrims are usually vaccinated at primary healthcare clinics, whereas Arab-Israeli pilgrims are usually vaccinated at travel clinics or primary healthcare clinics [7].

Participation of both Palestinian and Arab-Israeli pilgrims are limited by the Hajj quota; set at 7000 for Palestinian pilgrims and 3500 for Arab-Israelis, respectively. A decision to grant an exit permit for the round-trip journey to the Kaaba is given based on a priority list, with older applicants receiving higher priority. This has resulted in thousands of Hajjis being denied exit permits, with some of them having to wait several decades in order to fulfill their pilgrimage.

The excruciatingly long waiting period coupled with the substantial financial burden have given rise to an important heath trend - those who eventually get their exit permits are often elderly who often opt to travel despite their significantly baseline health problems, which makes them vulnerable to communicable disease, injuries, and exacerbation of known chronic illnesses.

To the best of our knowledge, no previous articles were published to prospectively characterize the infectious and non-infectious morbidity among Arab-Israeli or Palestinian Hajj pilgrims. In this paper, we prospectively investigated the occurrence of common health problems among Arab-Israeli and Palestinian Hajjis who travelled to complete their Pilgrimage during the 2019 Hajj seasons using a questionnaire administered before and after Hajj Travel.

\section{Patients And Methods}

\section{Study design}

A prospective observational questionnaire-based study.

\section{Study population}

The study population included Hajj pilgrims aged 18 or older who agreed to participate and from whom an informed consent was obtained. The pilgrims were both Arab-Israeli and Palestinians residing mainly in Jerusalem and in the Central District of Israel.

\section{The questionnaire}


Questionnaires were distributed to Hajj pilgrims on 3 different time occasions - within one month before Hajj travel and then 1 week and 4 weeks after returning. The Pre-travel Questionnaire evaluated different aspects such as demographic characteristics (age, gender, country of birth, location of residence, profession, level of education), pre-travel morbidity (chronic diseases including diabetes, hypertension, chronic kidney disease, chronic obstructive pulmonary diseases, malignancies), means of transportation to Mecca, duration of stay and living condition during their stay. In the post-return questionnaire all morbidities (infectious and non-infectious) were recorded, including outpatient visits and hospitalization during their stay and during the 4-week period after their return to Israel. The study was approved by the Sheba Medical Center local ethics committee (Approval code 5982-19-SMC).

\section{Statistical analysis}

Statistical analysis was performed using IBM SPSS statistics software, Version 23. Continuous variables were computed as mean \pm standard deviation, while categorical variables were recorded as percentages where appropriate. Such variables were compared between two groups. Alpha was set at the p-value critical cutoff of 0.05 and Comparison between categorical groups was carried out with the use of the Pearson Chi-Square test, and comparison of means between groups was analyzed by independent $t$-test. Mann-Whitney test was used for nonparametric analysis.

\section{Results}

One hundred and eleven pilgrims were recruited in the initial questionnaire while 104 hajjis completed the post-travel questionnaire thus yielding a completion rate of $93.6 \%$. The demographic characteristics of enrolled hajjis and the characteristics of their Hajj Journey are presented in table (1) below. Altogether, Respondents had a mean age of $49.5( \pm 9.137)$ years with a sex ratio M/F of 1.3. The Mean duration of travel was 18.7 days (13-36d).

Figure (1) illustrates the baseline chronic illnesses that were reported among the hajjis. Forty-three (38.7\%) enrolled participants reported having a chronic illness prior to their travel. The most common chronic illness reported among the travelling pilgrims was diabetes (21.6\%). Twenty-three of the participants $(20.6 \%)$ were smokers. Thirty $(28 \%)$ pilgrims received the seasonal influenza vaccine.

Among the 104 hajjis (93\%) who completed the post-travel questionnaire, fifty (45\%) were on regular medications, the majority of whom $(74.5 \%)$ did adhere to taking their medications regularly. Ninety-seven pilgrims (93.3\%) adhered to drinking mineral water and 100 pilgrims $(96.2 \%)$ reported eating hotelprepared meals only. The vast majority of male hajjis (83\%) used disposable single-use razor blades for the ritual shaving.

A total of $69(66.3 \%)$ pilgrims reported at least one health problem, of which 27 (38.6\%) sought medical attention, mostly (about 75\%) in Saudi Arabia, but also (about 25\%) in Israel upon returning (Figure 2). Of 
those who sought medical attention, $11 \%$ reported cough and fever.

As shown in figure $3 a$, the most commonly reported health problem among the travelling hajjis was cough, that was seen in 56 hajjis (53.8\%). Of those, 12 pilgrims (11.5\%) reported having both fever and cough. A total of 5 hajjis (4.8\%) were hospitalized (1 in Saudi Arabia and 4 in Israel upon returning) including 3 pilgrims $(2.9 \%)$ with life-threatening conditions - central venous associated infection and gram-negative bacteremia in a dialysis patient, acute appendicitis and febrile neutropenia.

Figure $3 \mathrm{~b}$ shows the health problems recorded at the subsequent questionnaire at week 4 and resembles the trend that was observed in the week 1 questionnaire, with a significant resolution of the majority of complaints apart from cough that persisted in almost $23 \%$ of pilgrims 4 weeks after returning from the pilgrimage (figure $2 b$ ).

With regards to symptoms reported among the travelling pilgrims, no statistically significant differences were observed between different age or gender groups. In addition, the baseline health status, smoking status, vaccination status and the means of travel had no statistically significant influence on the symptoms reported by travelling hajjis.

Finally, Pilgrims who received a medical counselling prior to their travel sought medical attention less (25.6\%) than those who didn't (57.9\%), and this was statistically significant $(p=0.014)$. No differences were observed with regards to seeking medical attention between gender, age groups or health status (as seen in table 2).

\section{Discussion}

A high rate of morbidity was reported among Arab-Israeli and Palestinian Hajj pilgrims, with $66.3 \%$ reporting at least one health problem. Our population was characterized by a high prevalence of chronic diseases such as diabetes, hypercholesterolemia, and hypertension - a feature that was observed in numerous previous studies. Similarly, the spectrum of morbidity observed among our cohort bares a strong resemblance to the morbidity seen in other hajj cohorts travelling from other countries [3][8]. This is an important finding with several important health implications. First, this may help generalize the recommendations adapted worldwide to all travelling pilgrims, regardless of the countries they're travelling from. Second, it emphasizes the importance of environmental factors such as overcrowding, continuous close contact and humid weather conditions as the key contributors to morbidity during the hajj season.

Cough was the most common health problem reported in our cohort (53.8\% of the travelling hajjis). Interestingly, Gautret et al reported a cough attack rate of 51\% among French pilgrims in 2007, which was consistent with the results of their antecedent survey from

2006 [8][9]. Cough was even more common among Malaysian pilgrims, reported in $91.5 \%$ of them in a study conducted during the same Hajj season, with the variation in incidence attributed mainly to the 
severe climatic change for Malaysian Hajj pilgrims [10]. Such variation in the incidence of cough among different cohorts may reflect differences in study design, study population, rates of vaccination and the seasonal variation of upper respiratory tract infections, but "Hajj cough" is universally common among the travelling pilgrims to the extent that it is considered almost de rigueur by most.

A significant proportion of the travelling pilgrims reported cough again at 4 weeks post-travel. The persistence of "Hajj cough" is a particularly interesting phenomenon that may be due to several possible etiologies. As Upper respiratory tract infections tend to resolve in a relatively short time-frame, possibilities to consider may include non-viral agents such as pertussis that has been established as a cause of prolonged cough among hajjis, with high acquisition rates of pertussis reported among pilgrims with no immunity to pertussis prior to travel or those with prolonged stay at Mecca [11]. Other possible etiologies are atypical pulmonary infections such as mycoplasma and even tuberculosis, which has previously been reported in an Arab-Israeli pilgrim returning from Hajj [12]. Because of the different causative agents that are thought to be involved and since vaccination alone is not sufficient to prevent respiratory illness in travelling pilgrims, behavioral measures such as hand hygiene with nonalcoholic hand rubs, wearing a face mask, cough etiquette represent the most realistic measures to prevent acute respiratory illnesses during the pilgrimage.

As seen in figure 2(a), twenty percent of the subjects in our cohort reported musculoskeletal complaints. We didn't observe any cases of major trauma in our cohort, despite being one of the major causes of morbidity and mortality during the Hajj [3]. One plausible explanation to muscle pain being a common symptom among the travelling hajjis is the long distance travelled by pilgrims during the Hajj rituals such as Tawaf (the circumambulation seven times around the Kaa'ba), Sa'ay (walking seven times between the hills of Safa and Marwa) and the stoning of the pillars.

Diarrheal illnesses were encountered in about $11 \%$ of our cohort, much higher than the incidence encountered in the large Iranian studies (2.7\% in 2004 and $2.75 \%$ in 2005) and by Gautret et al in French pilgrims (4.5\%) [13][8]. The majority of our hajjis (93.3\%) adhered to drinking mineral water and $96.2 \%$ reported eating Hotel-prepared meals only. Almost all cases of gastroenteritis were self-limited and none were hospitalized, and no cases of dysentery were reported in our cohort. Despite being a significant threat in the past, notably due to cholera outbreaks, recent data indicate a shift towards lower prevalence that may be largely attributed to the improved sanitary conditions in Saudi Arabia, the better health education among the travelling pilgrims with a heightened sense of hygiene [14]. During the hajj, hand washing is regularly carried out by pilgrims under at ritual purification, often called ablution (Wudu) that is performed in most cases before the five daily obligatory prayers. Consequently, hand hygiene compliance is high among pilgrims during hajj [15].

Pilgrims must be educated regarding measures to prevent traveler's diarrhea and self-treatment of diarrheal disease. Adequate rehydration is vital. Frequent Handwashing with soap or alcohol-based hand rubs remains the simplest but most effective measure to prevent the transmission of enteric events among Hajj pilgrims. A recent study conducted on French pilgrims on 2016 found a lower prevalence of 
Enteropathogenic E. coli (EPEC) in pilgrims who declared washing their hands more frequently at the Hajj than usually as compared to others [16].

About $22 \%$ of our study cohort had diabetes mellitus. We observed a single episode of hypoglycemia. No cases of diabetic ketoacidosis or Non-Ketotic Hyperosmolar state were identified. This is similar to the results found by Gautret et. a/ where $2.6 \%$ of the individuals suffering from diabetes had cases of unstable diabetes (defined as extremes of blood sugar levels) [8]. Muslims with diabetes planning to make Hajj should make a pre-Hajj travel clinic visit to carefully construct a diabetes management plan tailored to the unique health challenges of the Hajj. Diabetic patients should ensure adequate prescriptions for all medications, including syringes and needles. A diabetes emergency kit should include easily accessible carbohydrate sources to counter hypoglycemia, glucometer and test strips. Finally, durable and protective footwear are necessary to avoid minor foot trauma that can lead to infections [17].

Acute cardiovascular system disorders were not observed among our cohort, despite high proportion of pre-travel cardiovascular morbidity in our cohort ( $19 \%$ of the study participants), and despite being reported as the most common cause of death during Haj by the Saudi Ministry of health [18].

Five patients (4.8\%) of the study population were admitted to hospitals - 1 in Saudi Arabia and 4 in Israel. Among the pilgrims admitted, 3 had life-threatening health conditions: one had undergone appendectomy for acute appendicitis, one dialysis patient was hospitalized in an intensive care setting with gram negative bacteremia caused by infection of the central venous dialysis catheter that necessitated the removal of the dialysis line and the administration of broad-spectrum IV antibiotics. The third pilgrim was a known case of hematological malignancy who was admitted for the investigation of febrile neutropenia. The two other hajjis admitted were a couple with pneumonia that required a short hospitalization. All the admitted patients but one had significant co-morbidities, but no deaths were observed and all of the admitted pilgrims were discharged in a good clinical condition. Pneumonia was the leading cause of admissions among other cohorts during earlier hajj seasons [19] [20].

We evidenced a particularly high referral to outpatient clinics and ER visits in those who didn't receive a pre-travel medical counselling (57.9\%) compared to those who did (25.6\%), a finding that was statistically significant $(p=0.01)$. This highlights the importance of educating the pilgrims on the potential health risks of Hajj pilgrimage prior to travelling and providing them with simple yet effective strategies to tackle the most common health issues encountered during the pilgrimage. As the number of Hajj pilgrims increase each year, one way to ensure this comes to fruition is to assign all the travelling pilgrims to specialized Hajj pre-travel clinics through direct cooperation with the authorized travel agencies. This may help ensure the complete vaccination of all travelling pilgrims and their education on health issues commonly encountered during hajj, preferably in an individualized pre-travel consultation by a qualified health personnel.

Eleven percent of our pilgrims had febrile respiratory illnesses after travelling to Saudi Arabia, which is consistent with the CDC definition of a probable case of MERS-CoV [21]. Although the majority of the cases diagnosed were reported from Saudi Arabia, no laboratory-confirmed cases of MERS-CoV were 
found among the returning hajis that suffered acute respiratory illnesses upon returning to their countries, despite vigorous surveillance [22][23][24].

The lack of testing among our returning pilgrims with febrile respiratory illnesses is particularly worrisome not only in the context of probable MERS-CoV missed cases but also in light of the recent emergence and spread of the new novel coronary virus, officially known as COVID-19, to the Middle East region. Officially declared by the WHO as a pandemic on the $11^{\text {th }}$ of March 2020, the potential spread of the new novel coronary viruses to Hajj attendees during the upcoming Hajj Season can potentially lead to a massive spread of this infection with devastating consequences. Indeed, in the face of the escalating threat of COVID-19, Saudi Arabia has made an unprecedented and courageous decision by temporarily suspending the Hajj and Umrah for the upcoming 2020 season, realizing that that the death toll from SARS-COV-2 has now surpassed the combined toll of 2003 severe acute respiratory syndrome (SARS) and Middle East respiratory Syndrome (MERS) combined [25].

Our study has several limitations, the main ones being the small number of participants and not having a "during Hajj" phase of the survey. Some degree of recall bias or self-reporting bias may have been present among the participants during the completion of post travel questionnaires but we tried to nullify that by interviewing our respondents at 2 different time frames after returning. In addition, we didn't investigate the specific pathogens causing respiratory tract or gastrointestinal infections but this was largely due the lack of funding as meticulous microbiological testing has significant costs. The relatively young mean age of our population with significant baseline morbidity may have impacted the ability to detect any statistically significant differences among different age groups, yet we think this is an accurately representative sample of people travelling from our region. Finally, the study was based on a limited number of subjects clustered mainly in east Jerusalem as pilgrims travelling from the west bank were difficult to reach having received their pre-travel vaccinations at different primary health clinics scattered in different Palestinian cities. Therefore, our results cannot be extrapolated to the whole population of pilgrims participating in the Hajj. Nevertheless, this is the first study to prospectively characterize the infectious and non-infectious morbidity in Palestinian and Arab-Israeli pilgrims travelling from our region and provides valuable information for future seasons.

\section{Declarations}

\section{Declaration of Interest}

The authors state they have no conflicts of interest to declare.

\section{Acknowledgments}

We would like to thank Mr. Hasan Ali for his active contribution in recruitment of pilgrims.

\section{References}


[1] Al-Tawfiq JA, Memish ZA. Mass gatherings and infectious diseases: prevention, detection, and control. Infect Dis Clin North Am 2012;26:725-37. https://doi.org/10.1016/j.idc.2012.05.005.

[2] Memish ZA, Al-Rabeeah AA. Public health management of mass gatherings: the Saudi Arabian experience with MERS-CoV. Bull World Health Organ 2013;91:899-899A. https://doi.org/10.2471/BLT.13.132266.

[3] Ahmed QA, Arabi YM, Memish ZA. Health risks at the Hajj. Lancet (London, England) 2006;367:1008-15. https://doi.org/10.1016/S0140-6736(06)68429-8.

[4] The number of Palestinian Pilgrims travelling to complete their Hajj pilgrimage in 2019 - 66102019. https://nn.ps/news/Palestine/2019/07/30/248531/. (accessed June 1, 2020).

[5] Ministry of Health in the Kingdom of Saudi Arabia. Health requirements and recommendationsfor travelers to Saudi Arabia for Hajj and Umrah 2019.

[6] Al-Tawfiq JA, Memish ZA. The Hajj 2019 vaccine requirements and possible new challenges. J Epidemiol Glob Health 2019;9:147-52. https://doi.org/10.2991/jegh.k.190705.001.

[7] Hajj Vaccines for travelling Palestinian pilgrims n.d.

http://palestinecabinet.gov.ps/GovService/ViewService?ID=441. (accessed June 1, 2020).

[8] Gautret P, Soula G, Delmont J, Parola P, Brouqui P. Common health hazards in french pilgrims during the hajj of 2007: A prospective cohort study. J Travel Med 2009;16:377-81. https://doi.org/10.1111/j.1708-8305.2009.00358.x.

[9] Gautret P, Yong W, Soula G, Gaudart J, Delmont J, Dia A, et al. Incidence of Hajj-associated febrile cough episodes among French pilgrims: a prospective cohort study on the influence of statin use and risk factors. Clin Microbiol Infect Off Publ Eur Soc Clin Microbiol Infect Dis 2009;15:335-40. https://doi.org/10.1111/j.1469-0691.2009.02816.x.

[10] Deris ZZ, Hasan H, Sulaiman SA, Wahab MSA, Naing NN, Othman NH. The prevalence of acute respiratory symptoms and role of protective measures among Malaysian hajj pilgrims. J Travel Med 2010;17:82-8. https://doi.org/10.1111/j.1708-8305.2009.00384.x.

[11] Wilder-Smith A, Earnest A, Ravindran S, Paton Nl. High Incidence of Pertussis among Hajj Pilgrims. Clin Infect Dis 2003;37:1270-2. https://doi.org/10.1086/378748.

[12] Avnon LS, Jotkowitz A, Smoliakov A, Flusser D, Heimer D. Can the routine use of fluoroquinolones for community-acquired pneumonia delay the diagnosis of tuberculosis? A salutary case of diagnostic delay in a pilgrim returning from Mecca. Eur $\mathrm{J}$ Intern Med 2006;17:444-6. https://doi.org/10.1016/j.ejim.2006.02.016. 
[13] Meysamie A, Ardakani HZ, Razavi SM, Doroodi T. Comparison of mortality and morbidity rates among Iranian pilgrims in Hajj 2004 and 2005. Saudi Med J 2006;27:1049-53.

[14] Gautret P, Benkouiten S, Sridhar S, Al-Tawfiq JA, Memish ZA. Diarrhea at the Hajj and Umrah. Travel Med Infect Dis 2015;13:159-66. https://doi.org/10.1016/j.tmaid.2015.02.005.

[15] Benkouiten S, Brouqui P, Gautret P. Non-pharmaceutical interventions for the prevention of respiratory tract infections during Hajj pilgrimage. Travel Med Infect Dis 2014;12:429-42. https://doi.org/10.1016/j.tmaid.2014.06.005.

[16] Sow D, Dogue F, Edouard S, Drali T, Prades S, Battery E, et al. Acquisition of enteric pathogens by pilgrims during the 2016 Hajj pilgrimage: A prospective cohort study. Travel Med Infect Dis 2018;25:2630. https://doi.org/10.1016/j.tmaid.2018.05.017.

[17] Alsafadi H, Goodwin W, Syed A. Diabetes care during Hajj. Clin Med 2011;11:218-21. https://doi.org/10.7861/clinmedicine.11-3-218.

[18] Health statistics. Health, S.M.o. 2005.

[19] Madani TA, Ghabrah TM, Al-Hedaithy MA, Alhazmi MA, Alazraqi TA, Albarrak AM, et al. Causes of hospitalization of pilgrims in the Hajj season of the Islamic year 1423 (2003). Ann Saudi Med 2006;26:346-51. https://doi.org/10.5144/0256-4947.2006.346.

[20] Al-Ghamdi SM, Akbar HO, Qari YA, Fathaldin OA, Al-Rashed RS. Pattern of admission to hospitals during muslim pilgrimage (Hajj). Saudi Med J 2003;24:1073-6.

[21] Centers for Disease Control and Prevention. Middle East Respiratory Syndrome: Interim Guidance for Healthcare Professionals. Centers Dis Control Prev 2015.

http://www.cdc.gov/coronavirus/mers/interim-guidance.html.

[22] Ma X, Liu F, Liu L, Zhang L, Lu M, Abudukadeer A, et al. No MERS-CoV but positive influenza viruses in returning Hajj pilgrims, China, 2013-2015. BMC Infect Dis 2017;17:1-4. https://doi.org/10.1186/s12879-017-2791-0.

[23] Amin M, Bakhtiar A, Subarjo M, Aksono EB, Widiyanti P, Shimizu K, et al. Screening for Middle East respiratory syndrome coronavirus among febrile Indonesian Hajj pilgrims: A study on 28,197 returning pilgrims. J Infect Prev 2018;19:236-9. https://doi.org/10.1177/1757177418765634.

[24] Koul PA, Mir H, Saha S, Chadha MS, Potdar V, Widdowson M-A, et al. Respiratory viruses in returning Hajj \& Umrah pilgrims with acute respiratory illness in 2014-2015. Indian J Med Res 2018;148:329-33. https://doi.org/10.4103/ijmr.IJMR_890_17.

[25] Ahmed QA, Memish ZA. The cancellation of mass gatherings (MGs)? Decision making in the time of COVID-19. Travel Med Infect Dis 2020;34:101631. https://doi.org/10.1016/j.tmaid.2020.101631. 


\section{Tables}

Table 1 - Demographic and Travel Characteristics of Travelling Hajj pilgrims

\begin{tabular}{|lc|}
\hline Demographic Characteristic & \\
Age - years & $49(29-69)$ \\
Median (Range) & \\
Sex - No. (\%) & \\
Males & \\
Nationality - No. (\%) & \\
Arab Israeli & $31(27.9)$ \\
Palestinians & $60(72.1)$ \\
Travel Characteristics & \\
\hline No & \\
Mean travel duration in days (Range) & \\
Method of Travel- No. (\%) & \\
\hline
\end{tabular}

Page $11 / 13$ 
Table 2 - Health problems and seeking medical care with regards to different variables.

\begin{tabular}{|c|c|c|c|c|c|c|c|}
\hline & & $\begin{array}{c}\text { Seek Medical } \\
\text { care } \\
n(\%)\end{array}$ & & $\begin{array}{c}\text { P- } \\
\text { value }\end{array}$ & $\begin{array}{c}\text { Any health } \\
\text { problems } \\
n(\%)\end{array}$ & & P-value \\
\hline & & Yes & no & & Yes & no & \\
\hline \multirow[t]{2}{*}{ Gender } & males & $11(33.3)$ & $22(66.7)$ & $0.70 \ddagger$ & $34(60.7)$ & $\begin{array}{c}22 \\
(39.3)\end{array}$ & $0.59 \neq$ \\
\hline & females & $11(37.9)$ & $18(62.1)$ & & $29(65.9)$ & $\begin{array}{c}15 \\
(34.1)\end{array}$ & \\
\hline \multirow[t]{2}{*}{ Age } & $<50$ & $13(32.5)$ & $27(67.5)$ & $0.50 \ddagger$ & $41(68.3)$ & $\begin{array}{c}19 \\
(31.7)\end{array}$ & $0.17 \ddagger$ \\
\hline & $>=50$ & $9(40.9)$ & $13(59.1)$ & & $22(55)$ & $18(45)$ & \\
\hline \multirow[t]{2}{*}{ health status } & $\begin{array}{c}\text { previously } \\
\text { healthy }\end{array}$ & $15(38.5)$ & $24(61.5)$ & $0.52 \ddagger$ & $39(61.9)$ & $\begin{array}{c}24 \\
(38.1)\end{array}$ & $0.76 \ddagger$ \\
\hline & chronic illness* & $7(30.4)$ & $16(69.6)$ & & $24(64.9)$ & $\begin{array}{c}13 \\
(35.1)\end{array}$ & \\
\hline \multirow[t]{2}{*}{$\begin{array}{c}\text { prior } \\
\text { counselling§ }\end{array}$} & yes & $11(25.6)$ & $32(74.4)$ & $0.014 \ddagger$ & $44(69.8)$ & $\begin{array}{c}19 \\
(30.2)\end{array}$ & $0.06 \ddagger$ \\
\hline & no & $11(57.9)$ & $8(64.5)$ & & $19(51.4)$ & $\begin{array}{c}18 \\
(48.6) \\
\end{array}$ & \\
\hline \multirow[t]{2}{*}{ prior vaccination } & yes & $6(40)$ & $9(60)$ & $0.60 \ddagger$ & $15(55.6)$ & $\begin{array}{c}12 \\
(44.4)\end{array}$ & $0.45 \ddagger$ \\
\hline & no & $14(32.6)$ & $\begin{array}{c}29 \\
(67.4)\end{array}$ & & $44(63.8)$ & $\begin{array}{c}25 \\
(36.2)\end{array}$ & \\
\hline
\end{tabular}

‡Chi-square test

*chronic illness = chronic kidney disease, chronic obstructive pulmonary disease, diabetes mellitus, hypertension, malignancies.

- prior counselling - prior medical debriefing about the potential health hazards that may complicate the health pilgrimage.

\section{Figures}




\section{Figures not provided with this manuscript version}

Figure 1

Figures not provided 